\title{
Leucoencefalopatia multifocal progressiva como manifestação inicial da síndrome da imunodeficiência adquirida
}

\author{
Progressive multifocal leukoencephalopathy \\ as initial manifestation of \\ acquired immunodeficiency syndrome
}

Marcus Aurelho de Lima, Fabiana Valente de Andrade, Renata Margarida

Etchebehere e Mario León Silva-Vergara

Resumo Relata-se caso de homem portador da Síndrome da Imunodeficiência Adquirida que apresentou quadro agudo e grave de Leucoencefalopatia Multifocal Progressiva (LMP) como primeira manifestação da Síndrome. A LMP foi caracterizada macro e microscopicamente e através de estudo imuno-histoquímico utilizando o anticorpo antivírus JC.

Palavras-chaves: Leucoencefalopatia multifocal progressiva. Síndrome da imunodeficiência adquirida. Sistema nervoso central. Vírus JC.

Abstract This is a report of a man with acquired immunodeficiency syndrome (AIDS) who presented acutely ill with severe progressive multifocal leukoencephalopathy (PML) as the first manifestation of AIDS. PML was diagnosed in the brain after gross and microscopical examination as well as by immunohistochemistry with an antibody against JC virus.

Key-words: Progressive multifocal leukoencephalopathy. Acquired immunodeficiency syndrome. Central nervous system. JC virus.

Trabalho realizado na Faculdade de Medicina do Triângulo Mineiro (FMTM), Uberaba, MG.

Disciplinas de Endocrinologia, Anatomia Patológica e Medicina Tropical/FMTM

Endereço para correspondência: Dr. Marcus Aurelho de Lima. Endocrinologia/HE/FMTM; Av. Getúlio Guaritá 130, Abadia, 38025-440 Uberaba, MG.

Fone: (034) 318-5292. Fax: (034) 312-6640.

E-mail: lima@mednet.com.br

Recebido para publicação em 10/02/98. 
A leucoencefalopatia multifocal progressiva (LMP) é uma doença neurológica rara e fatal de adultos causada pela infecção oportunista do papovavírus JC no sistema nervoso central (SNC)17 20, mais especificamente nos oligodendrócitos, causando desmielinização progressiva5. A doença geralmente está associada à imunodeficiência relacionada a neoplasias, auto-imunidade, iatrogenia e, atualmente, à Síndrome da Imunodeficiência Adquirida (SIDA)14 16 19. Aproximadamente, 200 casos tinham sido relatados antes do aparecimento da SIDA8.

A LMP afeta de 5 a $10 \%$ dos pacientes com SIDA4 10 15. As lesões da LMP na SIDA são semelhantes àquelas que ocorrem em outras doenças básicas, porém as alterações na SIDA podem ser atipicamente mais graves, mais extensas e mais necrosantes do que nos casos não associados à SIDA3. A apresentação clínica é insidiosa e as manifestações dependem da localização das lesões7 13.

Tendo a oportunidade de realizar necropsia de paciente portador da SIDA que desenvolveu quadro agudo de LMP como primeira manifestação da Síndrome, justifica-se sua apresentação pela contribuição que pode trazer ao melhor conhecimento da associação LMP e SIDA.

\section{RELATO DO CASO}

Homem branco, 25 anos, trabalhador braçal, natural e procedente de Frutal, MG, com sorologia positiva para o vírus da imunodeficiência adquirida (HIV) há 3 anos, foi internado pela primeira vez no Hospital Escola da Faculdade de Medicina do Triângulo Mineiro, Uberaba, MG, apresentando confusão mental, desorientação, paresia e parestesia no hemicorpo direito. Era usuário de drogas injetáveis. Apresentava crises convulsivas desde a infância.

No ato da internação, apresentava-se emagrecido, descorado $(++/ 4+)$, desidratado, orientado, eumétrico, com hemiparesia e hiperreflexia à esquerda, com predomínio braquial e hipotrofia generalizada.

Exames de laboratório. Hemograma: hemácias 3980000 $\mathrm{mm}^{3}$; hemoglobina $9,7 \mathrm{~g} / \mathrm{dl}$; hematócrito $38 \%$; plaquetas $465000 / \mathrm{mm}^{3}$; leucócitos $8200 / \mathrm{mm}^{3}$ com $13 \%$ de bastonetes, $70 \%$ de neutrófilos segmentados, $6 \%$ de eosinófilos, $0 \%$ de basófilos, $6 \%$ de linfócitos e $5 \%$ de monócitos. Urina: $\mathrm{pH} 7,0$; densidade 1022; elementos anormais ausentes; células epiteliais raras; leucócitos 2000/ml; hemácias $15000 / \mathrm{ml}$; presença de muco. Punção de líquido céfalo-raquidiano à internação: aspecto opalescente; células 3; hemácias $560 / \mathrm{mmc}$; glicose $45 \mathrm{mg} / \mathrm{dl}$; cloro $684 \mathrm{mg} / \mathrm{dl}$; proteínas $50 \mathrm{mg} / \mathrm{dl}$; tinta da China não realizada. Métodos de ELISA, imunofluorescência e hemaglutinação para Trypanosoma cruzi: não reagentes. Monoteste não reagente. Gama glutamil transferase: $32 \mathrm{U} / \mathrm{I}$. VDRL e FTA-ABS não reagentes. Reação de Imunofluorescência Indireta para Toxoplasma gondii: IgM não reagente e IgG 1:256. Sorologia para HIV pelo método de Elisa: título > 3000 (cutoff: 0,145) em duas amostras, confirmado pelo teste de Western Blot. Pesquisa de anticorpos antivírus C da hepatite: título $1335 \mathrm{ng} / \mathrm{ml}$ (cutoff 0,140 ); antígeno Austrália negativo. Punção de líquido céfalo-raquidiano 6 dias após a internação: coloração avermelhada; células 3; hemácias 2474/mm3; glicose $77 \mathrm{mg} / \mathrm{dl}$; cloro $743 \mathrm{mg} / \mathrm{dl}$; proteínas $84 \mathrm{mg} / \mathrm{dl}$; Tinta da China negativa; líquido xantocrômico após centrifugação. Tomografias computadorizadas (TC) de crânio (3 dias após a internação e um dia anterior ao óbito) mostraram imagem hipodensa na região fronto-parietal à direita, associada a edema (Figura 1).

Apesar da imagem tomográfica não ser compatível, iniciou-se esquema para toxoplasmose com sulfadiazina, pirimetamina, ácido folínico, anticonvulsivantes e diuréticos osmóticos.

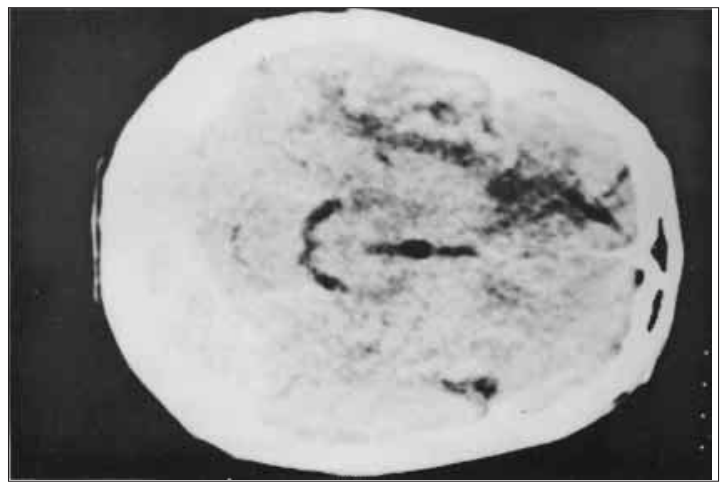

Figura 1 - Tomografia computadorizada de crânio mostrando imagem hipodensa na região frontoparietal à direita associada à edema. 
Durante a evolução, apresentou três crises convulsivas tônico-clônicas generalizadas com liberação de esfíncter urinário no dia da internação, com lenta recuperação da consciência na primeira crise e, após as outras, começou a mostrar sonolência, hemiparesia à esquerda $e$ disfasia. Houve piora progressiva do estado geral, desorientação, perda da capacidade cognitiva e sonolência. Voltou a apresentar diarréia, evoluindo em mau estado geral, não respondendo a estímulos verbais, com taquipnéia (freqüência respiratória de 56 incursões respiratórias por minuto), agitação e pressão arterial de $90 \mathrm{x}$ $40 \mathrm{mmHg}$, vindo a falecer oito dias após a internação.

Necropsia: cadáver com idade aparente de 30 anos medindo $1,70 \mathrm{~m}$ e pesando $41 \mathrm{~kg}$, em péssimo estado nutricional (índice de massa corporal de 14,19kg/m2). Mucosas descoradas. Dentes em precário estado de conservação. Venóclise cubital à direita; linfonodos palpáveis nas cadeias cervical posterior bilateralmente e supraclavicular à esquerda e em região inguinal bilateral, móveis, elásticos e pequenos, variando de 1 a $1,5 \mathrm{~cm}$.

Os achados fundamentais foram vistos no SNC. O encéfalo pesava $1360 \mathrm{~g}$ e a superfície externa mostrava giros alargados e achatados com apagamento ou superficialização de sulcos e hérnia de amígdalas cerebelares. À superfície de corte, verificou-se necrose da substância branca do hemisfério direito estendendo-se desde o lobo frontal até o occipital, com acometimento principalmente do lobo temporal e formação de cavidade (Figura 2). A córtex apresentava-se

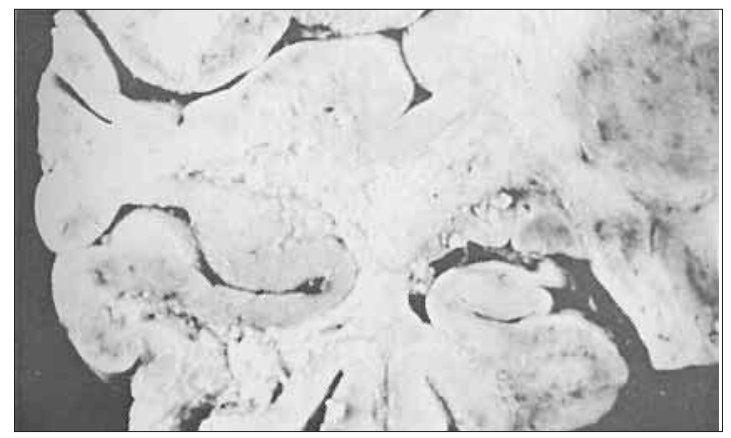

Figura 2 - Superfície de corte do lobo temporal direito apresentando necrose da substância branca (centro) com formação de cavidade (inferior). preservada. Ao exame microscópico, foram observados oligodendrócitos grandes e tumefeitos, com núcleos borrados e inclusões acidófilas (Figura 3 ). Estas células eram

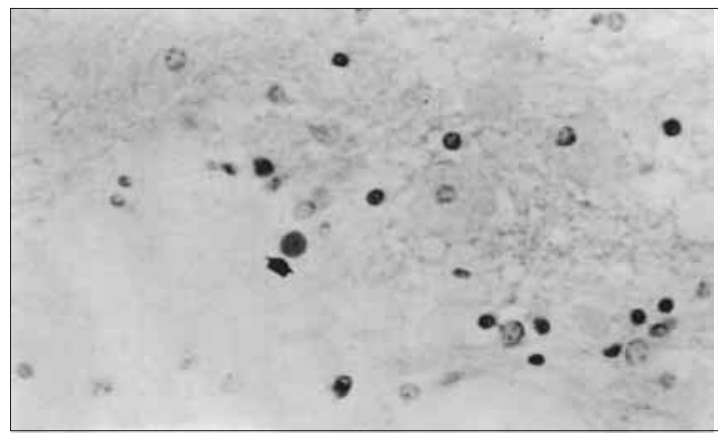

Figura 3 - Aspecto microscópico da periferia das áreas de necrose onde se observa oligodendrócito grande e tumefeito com núcleo borrado e com inclusão acidófila (seta) $(H E, 400 x)$.

encontradas em torno dos focos de necrose da substância branca contendo histiócitos espumosos e, em algumas áreas, havia proliferação de astrócitos (Figura 4). A pesquisa

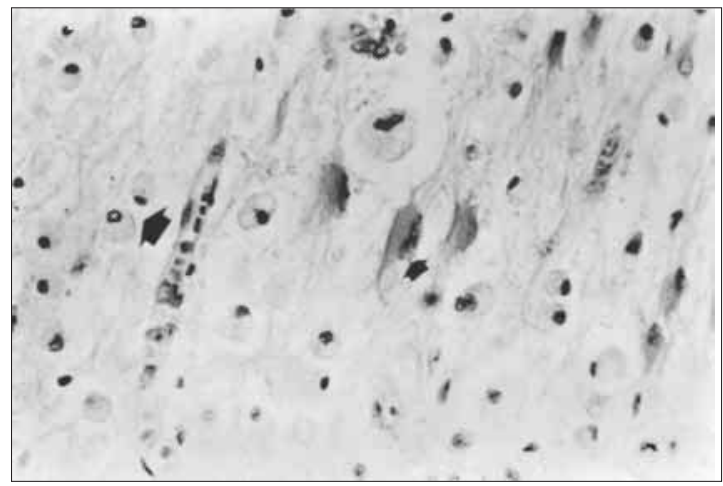

Figura 4 - Detalhe da periferia das áreas de necrose da substância branca mostrando histiócitos espumosos (seta maior) ao lado de proliferação de astrócitos (seta menor) (HE, 400X). 
do vírus JC, através do método imunohistoquímico, revelou-se positiva em oligodendrócitos (Figura 5), comprovando-se o diagnóstico de leucoencefalopatia multifocal progressiva.

Foram ainda diagnosticados: 1) gastroenterocolite por Candida $s p$; 2) broncopneumonia bacteriana (cocos gram positivos, provavelmente pneumococo); 3) hidrotórax bilateral $(100 \mathrm{ml}$ à direita e $150 \mathrm{ml}$ à esquerda) e hidropericárdio(50ml); 4) depleção linfóide generalizada; 5) adrenalite esquerda, gastrite e colite por citomegalovírus; 6) esôfago com alterações citológicas sugestivas de infecção por papilomavírus.

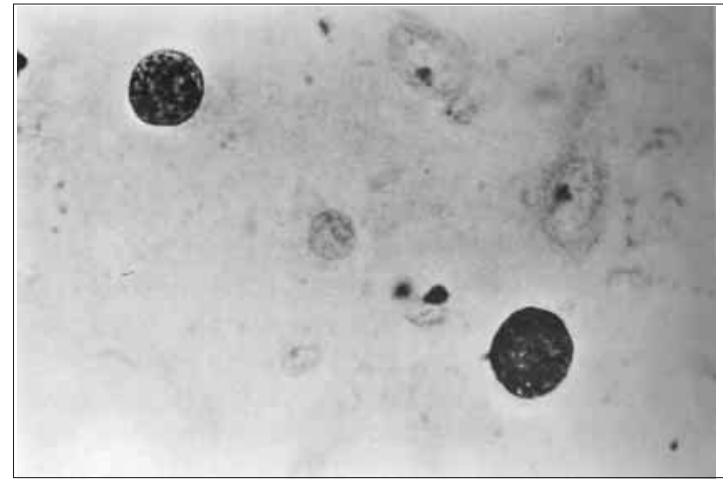

Figura 5 - Pesquisa do vírus JC, através do método imuno-histoquimico, positiva em oligodendrócitos (1000x).

\section{DISCUSSÃO}

O presente relato descreve paciente com SIDA que apresentou LMP, confirmada à necropsia, a qual, ao que parece, com evolução rápida.

O diagnóstico de LMP foi caracterizado pelos aspectos morfológicos, método imunohistoquímico e retrospectivamente pelos achados clínicos de déficit neurológico sem evidência de aumento de pressão intracraniana. Os achados anatomopatológicos de depleção linfóide generalizada, candidíase e citomegalovirose, além da positividade dos testes sorológicos para HIV, sugerem que o paciente era portador de imunossupressão significativa decorrente da SIDA. Apesar de não termos a dosagem de subpopulações de linfócitos como critério para definição do estado imunitário deste paciente, as evidências acima descritas favorecem este diagnóstico.

A LMP apresenta início insidioso, evolui para o óbito entre 3 meses e 1 ano na maioria das vezes6. No presente caso, entretanto, a doença surgiu como um quadro neurológico de evolução rápida, sugerindo, clinicamente, a hipótese diagnóstica de neurotoxoplasmose, doença que geralmente tem uma história mais curta (menos que 2 semanas) ${ }^{14}$. Segundo Major et al13 e Berger et al7, a clínica apresentada pelos pacientes está intimamente relacionada com a localização e extensão das lesões. Desse modo, o quadro agudo da apresentação da LMP no caso em questão parece ser decorrente da ampla lesão necrosante acometendo a substância branca do hemisfério direito, desde o lobo frontal até o occipital, cujo aspecto microscópico sugeriu que a lesão, em sua totalidade, apresenta mesma idade, isto é, recente.

O vírus JC é causa de infecção assintomática freqüente durante a infância. Cerca de 70 a 90\% dos adultos são infectados pelo vírus JC podendo ser detectado até 30 a $40 \%$ por reação em cadeia da polimerase (PCR) na urina de adultos normais ${ }^{12}$. Apesar da hipótese de infecção primária não ter sido excluída, tem-se admitido que a doença resulte de reativação a partir de foco renal. Outra hipótese, seria a reativação de infecção latente no SNC de hospedeiros imunocomprometidos, baseada nos achados freqüentes por PCR no cérebro de pacientes com SIDA que não tinham evidências clínicas de LMP15.

O diagnóstico de LMP depende do quadro clínico de déficit neurológico focal sem evidência de aumento de pressão intracraniana, da identificação do vírus no tecido cerebral e dos achados à biópsia cerebral somados às imagens de desmielinização vistas à Ressonância Nuclear Magnética1 13. O encéfalo pode, externamente, se apresentar normal ou com alguma atrofia cortical. Aos cortes, a característica macroscópica mais importante é a presença de múltiplos focos acinzentados distribuídos na substância branca, às vezes confluentes e podendo apresentar-se com necrose ou mesmo cavitação ${ }^{16}$. As lesões incomumente podem acometer o cerebelo ou a substância cinzenta, porém podem ser vistas em qualquer parte do SNC14.

Aspectos que necessitam elucidação são o do comportamento, evolução e tratamento da LMP em pacientes com SIDA. A julgar pelos 
conhecimentos atuais, há indícios de que a LMP nestes pacientes deve se apresentar, semelhante ao presente caso, como doença grave e de alta letalidade, a exemplo do que ocorre na associação SIDA e infecções oportunistas que acometem SNC4 9. Recentes evidências mostram diferenças biológicas entre os genótipos do vírus JC, o que poderiam sugerir variabilidade no seu potencial para causar LMP1. O dano tecidual mais intenso em cérebros de pacientes com SIDA pode ser atribuído à transativação de um vírus pelo outro18. Em relação ao tratamento, não existe terapêutica efetiva para LMP e o prognóstico é pobre, com tempo médio de sobrevida, após o diagnóstico, de 3 meses a 1 ano. Mesmo assim, tem sido difundido que o tratamento agressivo antiviral deve ser instituído todas às vezes que for possível14.

O presente caso vem, também, mais uma vez demonstrar a importância da necropsia em portadores da SIDA. Sabendo-se da dificuldade do diagnóstico em vida de doenças que acometem o SNC, só se pode ter uma idéia exata da real freqüência com que estes processos se associam à SIDA tendo como base dados obtidos a partir de estudos completos, inclusive necropsia11 12 .

\section{AGRADECIMENTOS}

Agradecemos ao Professor Sebastian Lucas do Department of Histopathology, St. Thomas' Hospital, Lamberth Palace Road, Londres, Inglaterra pela realização do método imunohistoquímico para pesquisa do vírus JC no tecido encefálico e ao Professor Antonio C.O. Meneses da disciplina de Patologia Especial da FMTM pela revisão geral do trabalho e pelo resumo em inglês.

\section{REFERÊNCIAS BIBLIOGRÁFICAS}

1. Agustini HT, RyschkeWitsch CF, Stoner GL. Genotype profile of human polyomavirus JC excreted in urine of immunocompetent individuals. Journal of Clinical Microbiology 34:159-164, 1996.

2. Agustini HT, Ryschkewitsch CF, Mory R, Singer EJ, Stoner GL. JC Virus (JCV) genotypes in brain tissue from patients with progressive multifocal leukoencephalopathy (PML) and in urine from controls without PML: increase frequency of JCV type 2 in PML. The Journal of Infectious Diseases 176:18, 1997

3. Aksamit AJ, Gendelman HE, Orenstein JM, Pezeshkpou RGM. AIDS - associated progressive multifocal leukoencephalopathy (PML): comparison to non-AIDS PML with in situ hybridization and immunohistochemistry. Neurology 40:1073-78, 1990.

4. Anders $\mathrm{KH}$, Guerra WF, Tomiyasu U, Verity MA, Vinters HV. The neuropathology of AIDS. UCLA experience and review. American Journal of Pathology 124:537-558, 1986.

5. Astróm KE, Stoner LL. Early pathological changes in Progressive Multifocal Leukoencephalopathy - a report of two asymptomatic cases occurring prior to the AIDS epidemic. Acta Neuropathologica 88:93105, 1994.

6. Berger JR, Concha M. Progressive multifocal leukoencephalopathy, the evolution of a disease once considered rare. Journal of Neurovirology 1:518, 1995.

7. Berger JR, Kaszovitz B, Post MJ, Dickinson G. Progressive multifocal leukoencephalopathy associated with human immunodeficiency virus infection. A review of the literature with a report of sixteen cases. Annals of Internal Medicine 107:78-87, 1987.

8. Brooks BR, Walker DL. Progressive multifocal leukoencephalopathy. Neurologic Clinics 2:299-313, 1984.

9. Cornford ME, Holden JK, Boyd MC, Berry K, Vinters HV. Neuropathology of the acquired immune deficiency syndrome (AIDS). Report of 39 autopsies from Vancouver, British Columbia. Canadian Journal of Neurological Sciences 19:442-452, 1992.

10. Lang W, Miklossy J, Deruaz JP, Pizzolato GP, Probst A, Schaffner T, Gessaga E, Kleihues P. Neuropathology of the acquired immune deficiency syndrome (AIDS): a report of 135 consecutive autopsy cases from Switzerland. Acta Neuropathologica 77:379-390, 1989.

11. Lima MA, Santos JAM, Lazo J, Silva-Vergara ML, Santos LAM, Santos VM. Infecção por Cryptococcus limitada à próstata em paciente aidético com micobacteriose disseminada. Relato de necropsia. Revista da Sociedade Brasileira de Medicina Tropical 30:501-505, 1997.

12. Lima MA, Silva-Vergara ML, Demachki S, Santos JAM. Paracoccidioidomicose em paciente com infecção pelo vírus da imunodeficiência adquirida. Relato de necropsia. Revista da Sociedade Brasileira de Medicina Tropical 28:279-284, 1995.

13. Major E, Amemiya K, Tornatore CS, Houff SA, Berger JR. Pathogenesis and molecular biology of progressive 
multifocal leukoencephalopathy, the JC virusinvolved demyelinating disease of the human brain. Clinical Microbiology Reviews 5:49-73, 1992.

14. Perrons CJ, Chinn RJS, Lucas SB, Harrison MJG, Miller RF. Progressive multifocal leukoencephalopathy in patients with AIDS: detection of JC virus DNA in CSF and brain. Genitourinary Medicine 71:35-40, 1995.

15. Petito CK, Cho ES, Lemann W, Navia BA, Price RW. Neuropathology of acquired immunodeficiency syndrome (AIDS): an autopsy review. Journal of Neuropathology and Experimental Neurology 45:635-646, 1986.

16. Quinlivan EB, Norris M, Bouldin TW. Subclinical Central Nervous System Infection with JC Virus in Patients with AIDS. The Journal of Infectious Diseases 166:80-85, 1992.

17. Raine CS. Demyelinating diseases. In: Davis RL, Robertson DM (eds) Textbook of Neuropathology.
Williams \& Wilkins, Baltimore, 3aㅡ edição, p.627-714, 1997.

18. Schmidbauer M, Budka H, Shah KV. Progressive multifocal leukoencephalopathy in AIDS and in the pre-AIDS era. A neuropathological comparison using immunocytochemistry and in situ hibridization. Acta Neuropathologica 80: 375-380, 1990.

19. Sweeney BJ, Manji H, Miller RF, Harrison MJG, Gray F, Scaravilli F. Cortical and subcortical JC virus infection: two unusual cases of AIDS associated progressive multifocal leukoencephalopathy. Journal of Neurology, Neurosurgery, and Psychiatry 57:994997, 1994.

20. Sweeney BJ, Miller RF, Harrison MJG. Progressive multifocal leukoencephalopathy. British Journal of Hospital Medicine 50:187-192, 1993. 